\title{
Cost-effectiveness of bivalirudin versus heparin plus glycoprotein IIb/IIIa inhibitor in the treatment of acute ST-segment elevation myocardial infarction
}

\begin{abstract}
Schwenkglenks, Matthias ; Toward, Toby J ; Plent, Stephanie ; Szucs, Thomas D ; Blackman, Daniel J ;
\end{abstract} Baumbach, Andreas

\begin{abstract}
OBJECTIVE: To assess the cost-effectiveness of bivalirudin versus heparin and glycoprotein $\mathrm{IIb} / \mathrm{IIIa}$ inhibitor (H-GPI) in patients undergoing primary percutaneous coronary intervention (PPCI) for acute ST-segment elevation myocardial infarction (STEMI), from a UK health service perspective. DESIGN: Cost-utility analysis with life-long time horizon. MAIN OUTCOME MEASURES: Costs, quality-adjusted life-years (QALYs) and incremental cost-effectiveness. METHODS: Event risks and medical resource use data derived from the HORIZONS-AMI trial were entered into a decision analytic model. Clinical events until the end of year 1 (main model) or year 3 (alternative model) were modelled in detail. Adjustments were applied to approximate UK routine practice characteristics. Life expectancy of 1-year or 3-year survivors, health-state utilities, initial hospitalisation length of stay in the comparator strategy and unit costs were based on UK sources. Costs and effects were discounted at 3.5\%. RESULTS: The main model predicted bivalirudin and H-GPI patients to survive 11.52 and 11.35 (undiscounted) years on average, respectively, and to accrue 6.26 and 6.17 QALYs. Patient lifetime costs were $£ 267$ lower in the bivalirudin strategy ( $£ 12843$ vs $£ 13$ 110). Extensive sensitivity and scenario analyses confirmed these results to be robust. In probabilistic analysis, quality-adjusted survival was higher and costs were lower with bivalirudin in $95.0 \%$ of simulation runs. In $99.2 \%$, cost-effectiveness was better than $£ 20000$ per QALY gained. Results from the alternative model were fully consistent. CONCLUSION: The use of bivalirudin instead of H-GPI in STEMI patients undergoing PPCI is cost-effective, and offers a high probability of dominance. Background treatment with aspirin and clopidogrel is assumed.
\end{abstract}

DOI: https://doi.org/10.1136/heartjnl-2011-301323

Posted at the Zurich Open Repository and Archive, University of Zurich

ZORA URL: https://doi.org/10.5167/uzh-68105

Journal Article

Accepted Version

Originally published at:

Schwenkglenks, Matthias; Toward, Toby J; Plent, Stephanie; Szucs, Thomas D; Blackman, Daniel J; Baumbach, Andreas (2012). Cost-effectiveness of bivalirudin versus heparin plus glycoprotein IIb/IIIa inhibitor in the treatment of acute ST-segment elevation myocardial infarction. Heart (British Cardiac Society), 98(7):544-551.

DOI: https://doi.org/10.1136/heartjnl-2011-301323 
Cost-effectiveness of bivalirudin versus heparin plus glycoprotein IIb/IIIa inhibitor in the treatment of acute ST-segment elevation myocardial infarction

Matthias Schwenkglenks, ${ }^{1,2}$ Toby J Toward, ${ }^{3}$ Stephanie Plent, ${ }^{3}$ Thomas D Szucs, ${ }^{1}$ Daniel J Blackman, ${ }^{4}$ Andreas Baumbach ${ }^{5}$

${ }^{1}$ Institute of Pharmaceutical Medicine (ECPM), University of Basel, Basel, Switzerland; ${ }^{2}$ Institute of Social and Preventive Medicine, University of Zurich, Zurich, Switzerland; ${ }^{3}$ The Medicines Company, Abingdon, UK; ${ }^{4}$ Leeds General Infirmary, Leeds, UK, ${ }^{5}$ Bristol Heart Institute, Bristol, UK

\section{Corresponding author:}

Matthias Schwenkglenks, PhD MPH

University of Basel

Institute of Pharmaceutical Medicine (ECPM)

Klingelbergstrasse 61, 4056 Basel, Switzerland

Phone: +41612657696 Fax: +416126576 $\quad$ F5

E-mail: $\quad$ m.schwenkglenks@ unibas.ch

Running head: Cost-effectiveness of bivalirudin in STEMI patients

Keywords: Myocardial infarction, anticoagulants, bivalirudin, cost-benefit analysis, United Kingdom 


\section{ABSTRACT}

Objective: To assess the cost-effectiveness of bivalirudin versus heparin and glycoprotein IIb/IIIa inhibitor (H-GPI) in patients undergoing primary percutaneous coronary intervention (PPCI) for acute ST-segment elevation myocardial infarction (STEMI), from a UK health service perspective.

Design: Cost-utility analysis with life-long time horizon.

Main outcome measures: Costs, quality-adjusted life-years (QALYs) and incremental costeffectiveness.

Methods: Event risks and medical resource use data derived from the HORIZONS-AMI trial were entered into a decision analytic model. Clinical events until the end of year 1 (main model) or year 3 (alternative model) were modelled in detail. Adjustments were applied to approximate UK routine practice characteristics. Life expectancy of 1-year or 3-year survivors, health-state utilities, initial hospitalisation length of stay in the comparator strategy and unit costs were based on UK sources. Costs and effects were discounted at 3.5\%.

Results: The main model predicted bivalirudin and H-GPI patients to survive 11.52 and 11.35 (undiscounted) years on average, respectively, and to accrue 6.26 and 6.17 QALYs. Patient lifetime costs were $£ 267$ lower in the bivalirudin strategy ( $£ 12,843$ versus $£ 13,110)$. Extensive sensitivity and scenario analyses confirmed these results to be robust. In probabilistic analysis, quality-adjusted survival was higher and costs were lower with bivalirudin, in $95.0 \%$ of simulation runs. In $99.2 \%$, cost-effectiveness was better than $£ 20,000$ per QALY gained. Results from the alternative model were fully consistent.

Conclusion: The use of bivalirudin instead of H-GPI in STEMI patients undergoing PPCI is cost-effective, and offers a high probability of dominance. Background treatment with aspirin and clopidogrel is assumed. 


\section{INTRODUCTION}

Primary percutaneous coronary intervention (PPCI) has emerged as the preferred treatment option for acute ST-segment elevation myocardial infarction (STEMI) internationally and in the United Kingdom (UK).[1, 2] It has substantially reduced condition-related morbidity and mortality.[3] The addition of glycoprotein IIb/IIIa inhibitors (GPIs) to heparin-based anticoagulation has contributed to the decrease in ischaemic event rates but has increased the risk of bleeding complications.[4]

Bivalirudin, a direct and specific thrombin inhibitor, represents an alternative to the use of heparin and a GPI (H-GPI), against a common background of standard treatment with aspirin and clopidogrel. The Harmonizing Outcomes with Revascularization and Stents in Acute Myocardial Infarction (HORIZONS-AMI) trial (ClinicalTrials.gov number, NCT00433966), an international, prospective, randomised, open-label, parallel-group, Phase III clinical trial, established the comparative clinical efficacy and safety of this alternative in acute STEMI patients undergoing PPCI.[5] In this study, 57.2\% of 3,602 patients were enrolled in Europe and $2.8 \%$ in the UK. Bivalirudin showed a significant reduction in mortality and postprocedural bleeding events, with similar ischaemic event rates, at 30 days.[5] These effects were sustained at one year and three years.[6, 7] Furthermore, at three years, a significant reduction in repeat myocardial infarctions (MIs) was observed, mainly driven by non-Q-wave events. These results are consistent with findings from earlier randomised trials in related indications $[8,9]$ and retrospective analyses of large patient databases in the USA.[10, 11] There are no other randomised comparisons addressing the same clinical question. HORIZONS-AMI therefore formed the basis of European Medicines Agency approval of bivalirudin use for PPCI.

The health economic implications of bivalirudin use in STEMI patients undergoing PPCI in the UK have recently been assessed as part of a National Institute for Health and Clinical 
Excellence Single Technology Appraisal.[12] The present analysis of the incremental costs and cost-effectiveness of bivalirudin, conducted from a UK National Health Service perspective, was provided for the NICE appraisal.

\section{METHODS}

\section{Overview}

We performed a model-based cost-utility analysis with a life-long time horizon. The model evaluated incremental costs, and incremental clinical effectiveness expressed as qualityadjusted life-years (QALYs) gained. The bivalirudin-based and H-GPI-based treatment strategies were equivalent to those in the HORIZONS-AMI trial. Details and dosing rules have been reported elsewhere.[5] As defined in the trial protocol, provisional use of GPI was allowed in bivalirudin-treated patients that experienced no reflow or giant thrombus after PCI. All patients received aspirin and a thienopyridine prior to angiography.

The full HORIZONS-AMI dataset served as the main data source for this analysis. Absolute and relative clinical event risks and resource use parameters were derived from the HORIZONS-AMI intention-to-treat population. However, in order to adapt the data to the UK environment, assumptions on the use of radial arterial access; the proportional use of alternative GPIs, and initial length of stay in the H-GPI strategy were made. The long-term life expectancy of STEMI patients, utility values (i.e. quality of life weights) and unit costs were drawn from UK sources. A similar approach was previously used in a cost-effectiveness analysis of bivalirudin in the treatment of non-ST-segment elevation acute coronary syndrome (NSTE-ACS).[13] Details on model assumptions and input parameters are provided below 
and in an online supplement. Tables 1-3 list the parameters used in the main analysis as well as related ranges of variation and distributional assumptions required for sensitivity analysis.

\section{Model structure}

The health economic model was implemented using a published structure that combines a decision tree model with a Markov model to cover long-term survival.[13] Simulated patient cohorts entered the model at age 60.9 years, the mean age of the HORIZONS-AMI population, and were followed from primary hospitalisation to death. It was assumed that patients would not survive beyond age 100. The assumption was made that initial angiography was performed on all patients. The majority then received PPCI. Coronary artery bypass graft $(\mathrm{CABG})$ surgery or medical management were used in a small fraction. Between this initial treatment and the end of year 1, possible events included major and minor bleeding, ischaemic stroke, repeat MI, repeat revascularisation, or death (main model; fig. 1). 
Table 1. Absolute and relative clinical event risks

\begin{tabular}{|c|c|c|c|c|}
\hline & \multicolumn{2}{|c|}{ Patients $(\% ; 95 \% \mathrm{CI})^{\mathrm{a}}$} & \multicolumn{2}{|c|}{$\begin{array}{c}\text { Patients }(\% ; 95 \% \mathrm{CI})^{\mathrm{a}} \\
\text { Relative event risk; } 95 \% \mathrm{CI}^{\mathrm{a}}\end{array}$} \\
\hline $\begin{array}{l}\text { Type of clinical } \\
\text { event }\end{array}$ & H-GPI arm, 1 year & H-GPI arm, 3 years & $\begin{array}{l}\text { Bivalirudin arm, } 1 \\
\text { year } \\
\text { Bivalirudin versus } \\
\text { H-GPI }\end{array}$ & $\begin{array}{c}\text { Bivalirudin arm, } 3 \\
\text { years } \\
\text { Bivalirudin versus } \\
\text { H-GPI }\end{array}$ \\
\hline \multicolumn{5}{|c|}{ HORIZONS-AMI trial } \\
\hline $\begin{array}{l}\text { Non-CABG-related } \\
\text { major bleeding }\end{array}$ & $165(9.2 ; 7.9-10.6)$ & $185(10.3 ; 8.9-11.8)$ & $\begin{array}{c}103(5.7 ; 4.7-6.9) \\
0.63 ; 0.49-0.79\end{array}$ & $\begin{array}{c}121(6.7 ; 5.6-8.0) \\
0.66 ; 0.53-0.82\end{array}$ \\
\hline $\begin{array}{l}\text { Non-CABG-related } \\
\text { major access site } \\
\text { bleeding }^{c}\end{array}$ & $64(3.6 ; 2.7-4.5)$ & $67(3.7 ; 2.9-4.7)$ & $\begin{array}{c}34(1.9 ; 1.3-2.6) \\
0.53 ; 0.35-0.80\end{array}$ & $\begin{array}{c}39(2.2 ; 1.5-3.0) \\
0.58 ; 0.39-0.86\end{array}$ \\
\hline $\begin{array}{l}\text { Non-CABG-related } \\
\text { major non-access } \\
\text { site bleeding }^{c}\end{array}$ & $101(5.6 ; 4.6-6.8)$ & $118(6.5 ; 5.4-7.8)$ & $\begin{array}{c}69(3.8 ; 3.0-4.8) \\
0.68 ; 0.51-0.92\end{array}$ & $\begin{array}{c}82(4.6 ; 3.6-5.6) \\
0.70 ; 0.53-0.92\end{array}$ \\
\hline $\begin{array}{l}\text { Non-CABG-related } \\
\text { minor bleeding }\end{array}$ & $\begin{array}{c}256(14.2 ; 12.6- \\
15.9)\end{array}$ & $\begin{array}{c}262(14.5 ; 12.9- \\
16.3)\end{array}$ & $\begin{array}{c}137(7.6 ; 6.4-8.9) \\
0.54 ; 0.44-0.65\end{array}$ & $\begin{array}{c}146(8.1 ; 6.9-9.5) \\
0.56 ; 0.46-0.68\end{array}$ \\
\hline Ischaemic stroke & $18(1.0 ; 0.6-1.6)$ & $31(1.7 ; 1.2-2.4)$ & $\begin{array}{c}19(1.1 ; 0.6-1.6) \\
1.06 ; 0.56-2.01\end{array}$ & $\begin{array}{c}27(1.5 ; 1.0-2.2) \\
0.87 ; 0.52-1.46\end{array}$ \\
\hline $\begin{array}{l}\text { Repeat myocardial } \\
\text { infarction }\end{array}$ & $76(4.2 ; 3.3-5.3)$ & $135(7.5 ; 6.3-8.8)$ & $\begin{array}{c}62(3.4 ; 2.7-4.4) \\
0.82 ; 0.59-1.14\end{array}$ & $\begin{array}{c}105(5.8 ; 4.8-7.0) \\
0.78 ; 0.61-0.97\end{array}$ \\
\hline $\begin{array}{l}\text { Repeat } \\
\text { revascularisation }\end{array}$ & $155(8.6 ; 7.3-10.0)$ & $\begin{array}{c}302(16.8 ; 15.1- \\
18.6)\end{array}$ & $\begin{array}{c}174(9.7 ; 8.3-11.1) \\
1.12 ; 0.91-1.38\end{array}$ & $\begin{array}{c}337(18.7 ; 16.9- \\
20.6) \\
1.12 ; 0.97-1.29\end{array}$ \\
\hline Death & $86(4.8 ; 3.8-5.9)$ & $134(7.4 ; 6.3-8.7)$ & $\begin{array}{c}61(3.4 ; 2.6-4.3) \\
0.71 ; 0.52-0.98\end{array}$ & $\begin{array}{c}102(5.7 ; 4.6-6.8) \\
0.76 ; 0.59-0.98\end{array}$ \\
\hline
\end{tabular}

Estimates for $42.5 \%$ radial arterial access use as assumed in the base case analysis ${ }^{\mathrm{d}}$

\begin{tabular}{lcccc}
\hline $\begin{array}{l}\text { Non-CABG-related } \\
\text { major bleeding }\end{array}$ & $138(7.7 ; 6.5-9.0)$ & $157(8.7 ; 7.5-10.1)$ & $\begin{array}{c}89(4.9 ; 4.0-6.0) \\
0.64 ; 0.50-0.82\end{array}$ & $\begin{array}{c}104(5.8 ; 4.7-7.0) \\
0.67 ; 0.53-0.83\end{array}$ \\
\hline $\begin{array}{l}\text { Non-CABG-related } \\
\text { major access site }\end{array}$ & $37(2.1 ; 1.4-2.8)$ & $39(2.2 ; 1.5-2.9)$ & $20(1.1 ; 0.7-1.7)$ & $22(1.2 ; 0.8-1.8)$ \\
bleeding $^{c}$ & & & $0.53(0.32-0.93)$ & $0.58(0.34-0.95)$ \\
\hline $\begin{array}{l}\text { Non-CABG-related } \\
\text { minor bleeding }\end{array}$ & $147(8.2 ; 6.9-9.5)$ & $151(8.4 ; 7.1-9.8)$ & $79(4.4 ; 3.5-5.4)$ & $84(4.7 ; 3.7-5.7)$ \\
\end{tabular}

a Based on Kaplan-Meier estimates of event numbers for the HORIZONS-AMI intention-to-treat population. $\mathrm{H}-\mathrm{GPI}$ arm, $\mathrm{N}=1,802$; bivalirudin arm, $\mathrm{N}=1,800$. Limits of $95 \%$ CIs were used as ranges of variation in sensitivity analysis. In probabilistic sensitivity analysis, absolute (comparator strategy) event risks were represented by beta distributions and relative event risks by lognormal distributions.

b The HORIZONS-AMI definition of major bleeding included any of intracranial bleeding; intraocular bleeding; retroperitoneal bleeding; access site haemorrhage requiring surgery; haematoma $\geq 5 \mathrm{~cm}$; reduction in haemoglobin of $\geq 4 \mathrm{~g} / \mathrm{dL}$ without overt source; reduction in haemoglobin of $\geq 3 \mathrm{~g} / \mathrm{dL}$ with overt source; reoperation for bleeding; use of any blood transfusion.[5]

c Patients with a non-CABG major bleeding were classified as "access site" if they had a reported arterial access site or retroperitoneal bleeding, but no other major bleeding. The remainder of patients with a major bleeding were classified as "non-access site". An equivalent definition was recently used by Verheugt et al.[14]

d Estimates based on assumption of no access site bleedings in patients with radial arterial access (see Methods, section on Clinical event risks).

CABG, coronary artery bypass graft; H-GPI, heparin and glycoprotein IIb/IIIa inhibitor; HORIZONS-AMI, Harmonizing Outcomes with Revascularization and Stents in Acute Myocardial Infarction; n/e, not estimated. 
In order to avoid double counting, stent thrombosis was not modelled separately but its health impact and economic consequences are implicit by the modelling of the aforementioned events. In an alternative model, detailed modelling of clinical events was extended until the end of year 3 and the model structure was amended to maintain correct discounting despite this change. Average strategy-specific survival times of patients who died during year 1 or years 1-3 were taken into account. After the first or third year, survival was modelled based on published life expectancies. No further clinical events were modelled in detail. The Markov module used two disease stages (alive/dead). Cycle length was one year and a halfcycle correction was applied. Over the lifetime of the simulated cohorts, medical resource use, costs and QALYs accumulated. Costs and effects were discounted at 3.5\% per year.[15]

\section{Model inputs}

\section{Clinical event risks}

A full set of HORIZONS-AMI-based 1-year and 3-year comparator strategy event risks and of corresponding relative risks in the bivalirudin strategy (Table 1) was derived for the purpose of this analysis, and was found to be consistent with published results.[5-7]

Radial arterial access is more frequently used in the UK than in the HORIZONS-AMI patients $(214,5.9 \%)$. In order to account for this difference, the base case analysis assumed use of the radial route in $42.5 \%$ of patients, as per BCIS audit data.[16] The assumption was made that there would be no access site bleedings in these patients. The risk of non-access site bleeding was left unchanged.[17] The absolute bleeding risk in the comparator strategy and the resulting absolute effect of bivalirudin use on bleeding were hence reduced. The reduced risk difference for non-CABG major bleeding was assumed to lead to a proportional reduction in the length of stay difference between treatment strategies. 
Table 2. Utilities, medical resource use and long-term life expectancy

\begin{tabular}{|c|c|c|c|}
\hline Parameter & $\begin{array}{l}\text { Base case } \\
\text { value }\end{array}$ & $\begin{array}{l}\text { Range of variation in } \\
\text { sensitivity analysis }\end{array}$ & $\begin{array}{c}\text { Basis of } \\
\text { variation; } \\
\text { distribution in } \\
\text { PSA }\end{array}$ \\
\hline \multicolumn{4}{|l|}{ Life expectancy (years)[18-20] } \\
\hline 1 -year survivors, at end of year 1 & 11.26 & $8.45-14.08$ & \multirow[t]{2}{*}{ $\pm 25 \%$; triangular } \\
\hline 3 -year survivors, at end of year 3 & $9.37^{\mathrm{b}}$ & $7.03-11.71$ & \\
\hline \multicolumn{4}{|l|}{ Utility scores[21] } \\
\hline First year after STEMI event & 0.68 & $0.60-0.76$ & \multirow{2}{*}{$\begin{array}{c}\text { Utility } \\
\text { decrement } \\
\pm 25 \% \text {; triangular }\end{array}$} \\
\hline Subsequent years & 0.72 & $0.65-0.79$ & \\
\hline \multicolumn{4}{|l|}{ Anticoagulant use, $\%$ of patients } \\
\hline GPI (H-GPI; bivalirudin) & $95.3 \% ; 7.6 \%$ & $--^{c}$ & \multirow[t]{2}{*}{$\mathrm{n} / \mathrm{a}$} \\
\hline Bivalirudin (bivalirudin) & $96.9 \%$ & -- & \\
\hline \multicolumn{4}{|l|}{ Anticoagulant vial numbers, mean ${ }^{\mathrm{d}}$} \\
\hline Abciximab 10 mg (H-GPI; bivalirudin) & $3.07 ; 2.80$ & $3.03-3.11 ; 2.63-2.96$ & \multirow[t]{4}{*}{$95 \% \mathrm{CI}$; gamma } \\
\hline Eptifibatide $20 \mathrm{mg}$ (H-GPI; bivalirudin) & $1.88 ; 1.64$ & $1.84-1.92 ; 1.50-1.78$ & \\
\hline Tirofiban 12.5 mg (H-GPI; bivalirudin) & $1 ; 1$ & $--^{c}$ & \\
\hline Bivalirudin 250 mg (bivalirudin) & 1.23 & $1.21-1.26$ & \\
\hline \multicolumn{4}{|l|}{ Initial hospitalisation days, mean } \\
\hline Normal ward (H-GPI) & 2.45 & $2.28-2.65^{\mathrm{e}, \mathrm{f}}$ & \multirow[t]{2}{*}{$95 \% \mathrm{CI}$; gamma } \\
\hline ICU/CCU (H-GPI) & 1.95 & $1.76-2.16^{\mathrm{e}, \mathrm{f}}$ & \\
\hline Normal ward ( $\Delta$ bivalirudin $-\mathrm{H}-\mathrm{GPI})$ & 0.06 & $(-0.11)-0.32^{\mathrm{e}}$ & \multirow{2}{*}{$\begin{array}{l}95 \% \mathrm{CI} ; \\
\text { lognormal }^{\mathrm{g}}\end{array}$} \\
\hline ICU/CCU ( $\Delta$ bivalirudin $-\mathrm{H}-\mathrm{GPI}$ ) & -0.32 & $(-0.48)-(-0.17)^{\mathrm{e}}$ & \\
\hline
\end{tabular}

Estimates for $42.5 \%$ radial arterial access use as assumed in the base case analysis ${ }^{\mathrm{d}}$

Initial hospitalisation days, mean

Normal ward ( $\triangle$ bivalirudin $-\mathrm{H}-\mathrm{GPI})$

0.05

$(-0.21)-0.33^{\mathrm{e}}$

$95 \% \mathrm{CI}$;

ICU/CCU ( $\Delta$ bivalirudin - H-GPI)

$-0.25$

$(-0.49)-0.01^{\mathrm{e}}$

lognormal ${ }^{\mathrm{g}}$

a Only covering sensitivity analyses addressing the impact of parameter uncertainty. Additional scenario analyses are described in the text and in the online supplement.

b In the alternative model (with detailed modelling of adverse events until the end of year 3), overall survival in the comparator strategy was made identical to that seen in the main model.

c Varied in scenario analysis.

d Mean per patient in whom substance was used. The means shown originate from integer vials numbers at the patient level; non-integer values were increased to the next integer. For example, in the case of bivalirudin, this resulted in 1-3 vials per patient; in the vast majority of patients one vial was used.

e Based on bias-corrected bootstrap results using 1,000 replications.

f CIs do not take into account uncertainty in the H-GPI strategy overall length of stay assumption of 4.4 days.[22]

$\mathrm{g}$ In the model, these length of stay differences between strategies were implemented using multiplication factors that were assigned lognormal distributions.

$\mathrm{CI}$, confidence interval; $\Delta$, difference; H-GPI, heparin and glycoprotein IIb/IIIa inhibitor; ICU/CCU, intensive care unit/coronary care unit; n/a, not applicable; PSA, probabilistic sensitivity analysis; STEMI, ST-segment elevation myocardial infarction. 
Long-term survival

Long-term survival (beyond 1 year of follow-up in the main model and beyond 3 years in the alternative model) was based on an estimate using Nottingham Heart Attack Register (NHAR) data (Table 2).[20] Life-tables for England and Wales and the DEALE method were used to adjust this estimate to the increase in overall life expectancy since the NHAR data were collected, and to the mean age of the HORIZONS-AMI patients $(\mathrm{S} 1.1$, online).[18, 19] For those who survived the initial one-year or three-year period, long-term survival was assumed to be independent of the initial anticoagulation strategy.

\section{Utilities}

European Quality of Life-5 Dimensions-based health-state utilities from a single-centre UK study of 229 consecutive MI survivors (Table 2) were applied.[21] Valuation used standard UK time trade-off values and results were comparable to an independent set of UK estimates for PCI patients.[23]

\section{Medical resource use}

Anticoagulant vial use during the initial hospitalisation was derived from the HORIZONS-

AMI data (Table 2). Non-integer vial numbers at patient-level were increased to the next integer in order to cover waste of leftovers. Per-protocol GPI use was restricted to abciximab and eptifibatide. In order to reflect UK practice, the proportional use of alternative GPIs in UK PCI patients in 2009, i.e. abciximab, $73.0 \%$; eptifibatide, $8.1 \%$; tirofiban $18.9 \%$, was applied under the assumption of a GPI class effect and, hence, no changes in clinical effectiveness (S1.2, online).[16] Unfractionated heparin was disregarded due to its low cost.

Initial hospitalisation length of stay in the H-GPI strategy was assumed to be 4.4 days (compared to 7.2 days in HORIZONS-AMI).[22] The relative length of stay reduction observed in HORIZONS-AMI was applied to estimate length of stay in the bivalirudin 
strategy (Table 2; S1.3, online). In the base case analysis and applicable sensitivity analyses, the resulting difference was reduced in order to reflect the potential impact of a lower incidence of access site bleeding in conjunction with substantial radial arterial access use in the UK (see Clinical event risks).

Other resource items or drivers of resource use taken into account during the initial hospitalisation period and until the end of the first year (or third year, in the alternative analysis) included diagnostic angiograms, PCI and CABG procedures as well as clinical events (i.e. bleeding, ischaemic stroke, repeat MI and death; S1.4, online). After the first or third year, long-term cardiovascular-related medical resource use was represented by a literature-derived annual amount for a surviving patient. This amount was estimated from a published model of thrombolysis versus primary PCI in MI patients and designed to also incorporate the impact of repeat MIs and strokes on a summary basis (Table 3; S1.5, online).[24] The same amount was used to represent annual cardiovascular outpatient treatment and drug use during the first year or the first three years. 
Table 3. Unit costs

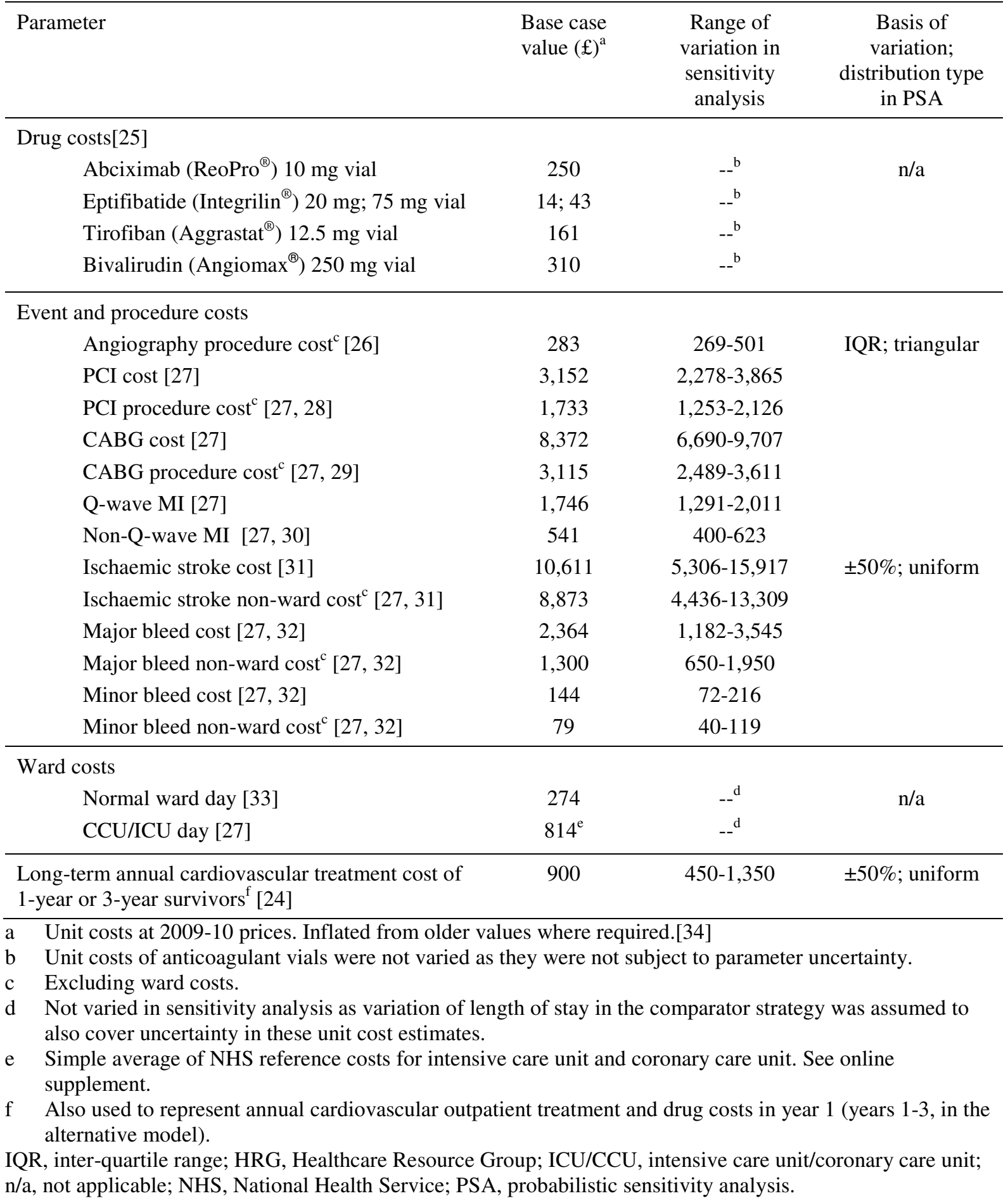

\section{Unit costs}

Unit costs were at 2009-10 prices; where necessary, older unit costs were inflation-corrected accordingly (Table 3; S1.5, online).[34] Public drug prices were taken from the MIMS website.[25] Ward costs and unit costs of angiography, PCI, CABG and repeat MI were based on NHS reference costs. The impact of PCI-related bleeding was partially covered by 
modelling initial hospitalisation ward costs. Additional examination and procedure costs of a HORIZONS-AMI major bleeding[5] were estimated to be $75 \%$ of the procedure cost of a repeat PCI. This estimate relied on a comparison of the impact of bleedings and repeat PCI procedures on hospitalisation costs, as assessed by multivariate regression methods (S1.5, online).[32, 35] HORIZONS-AMI minor bleedings were assumed to cost $6 \%$ of a major bleeding.[32]

\section{Sensitivity analysis}

Due to imperfect information on the costs and clinical effectiveness of the treatments studied, cost-effectiveness results are necessarily subject to uncertainty. This implies a potential to misinform decision makers. In order to assess this potential in the present case, major inputs into the main model were subjected to deterministic and probabilistic sensitivity testing. We included comparator strategy event risks, relative risks in the bivalirudin strategy, utilities, length of stay parameters, anticoagulant vial numbers, procedure costs and clinical event costs. Estimates of bleeding costs, of cardiovascular outpatient treatment and drug costs in the first year, and of long-term annual cardiovascular treatment costs were varied by $\pm 50 \%$ and with uniform distributions, to reflect increased parameter uncertainty. Ranges of variation and distribution types are available from Tables 1-3. A probabilistic analysis of the alternative model was additionally run and followed an equivalent approach.

Scenario analyses were performed in order to gain a better understanding of the applicability of main results to variations in UK practice. HORIZONS-AMI-based comparator strategy event risks were replaced with a tentative set of UK-based event risks compiled from different sources (S2.1, online). In order to assess the impact of varying use of radial arterial access, we replaced the value reported by BCIS, of $42.5 \%$, with $5.9 \%$ as seen in HORIZONSAMI and with an extreme assumption of $100 \%$. The effects of bivalirudin on bleeding occurrence and length of stay were adjusted accordingly. In an additional step, we also 
reduced the survival advantage for bivalirudin in patients with radial arterial access. For this purpose, the entire survival difference between strategies was conservatively assumed to be due to major bleeding avoidance. The mortality increase associated with major access-site bleeding was further assumed to be half of the increase associated with major non-access-site bleeding.[14, 36]

The proportional use of alternative GPI substances reported by BCIS[16] was replaced with abciximab $100 \%$ as assumed in the National Infarct Angioplasty Project (NIAP) modelling;[22] with abciximab 52.9\% and eptifibatide $47.1 \%$ as observed in HORIZONSAMI; and with eptifibatide $100 \%$, reflecting the lowest possible GPI cost. The initial hospitalisation was assumed to be of equal duration in both strategies. An extreme case scenario combined assumptions of $100 \%$ radial arterial access use, of a correspondingly reduced survival advantage for bivalirudin, of $100 \%$ eptifibatide use (in patients receiving a GPI) and of no difference in initial hospitalisation length of stay between strategies. The discount rate was varied from 0-6\%. (Additional analyses are described in S2.2, online.)

\section{Technical implementation}

Derivations of model inputs and related statistical analyses were performed in Stata/MP ${ }^{\circledR}$, Release 11 (Stata Corporation, College Station, TX, USA). The health economic model was implemented in TreeAge Pro 2009 Suite ${ }^{\circledR}$ (TreeAge, Inc., Williamstown, MA, USA). 


\section{RESULTS}

\section{Survival}

In the main and alternative models (with detailed modelling of clinical events until the end of year 1 and year 3), undiscounted survival after the index event in the bivalirudin strategy was predicted to be 11.52 and 11.56 years, respectively. Undiscounted survival in the H-GPI strategy was predicted to be 11.35 years in both cases. The implied small differences of 0.17 and 0.21 years arose from an absolute reduction of risk of death of $1.4 \%$ after year 1 (bivalirudin strategy, 3.4\%; H-GPI strategy, $4.8 \%$ ) and of $1.7 \%$ after year 3 (bivalirudin strategy, 5.7\%; H-GPI strategy, 7.4\%).

\section{Cost and cost effectiveness}

Cost differences between strategies and incremental cost-effectiveness results for the main and alternative models are shown in Table 4. In both models, the bivalirudin strategy was less costly than the H-GPI strategy. This was mainly driven by lower anticoagulant and initial hospitalisation ward costs. Procedure and clinical event costs were also lower. In contrast, cardiovascular outpatient treatment and drug costs during the initial one-year or three-year period, and long-term cardiovascular treatment costs, were higher in the bivalirudin strategy, as a reflection of improved survival. The life-long cost advantage for bivalirudin amounted to $£ 267$ and $£ 250$ in the main and alternative models, respectively, and went along with incremental gains of 0.09 and 0.11 QALYs. In combination, these results indicate a situation of dominance of bivalirudin over H-GPI, i.e. the bivalirudin strategy was more clinically effective and cost saving. 
Table 4. Cost (£ per patient) and cost-effectiveness results

\begin{tabular}{|c|c|c|c|c|c|c|}
\hline \multirow[t]{2}{*}{ Parameter } & \multicolumn{3}{|c|}{ Main model $^{\mathrm{a}}$} & \multicolumn{3}{|c|}{ Alternative model ${ }^{\mathrm{a}}$} \\
\hline & Bivalirudin & H-GPI & $\Delta$ & Bivalirudin & H-GPI & $\Delta$ \\
\hline Cost of bivalirudin & 370 & 0 & 370 & 370 & 0 & 370 \\
\hline Cost of GPI & 42 & 573 & -531 & 42 & 573 & -531 \\
\hline Ward cost (initial hospitalisation) & 2,064 & 2,259 & -195 & 2,064 & 2,259 & -195 \\
\hline $\begin{array}{l}\text { Procedure and clinical event cost } \\
\text { during year } 1 / \text { years } 1-3^{b, c}\end{array}$ & 2,484 & 2,509 & -25 & 2,903 & 2,939 & -36 \\
\hline $\begin{array}{l}\text { Cardiovascular outpatient } \\
\text { treatment and drug cost in year } 1 / \\
\text { years } 1-3^{c}\end{array}$ & 876 & 864 & 12 & 2,508 & 2,470 & 38 \\
\hline Total cost in year $1 /$ years $1-3^{c}$ & 5,837 & 6,204 & -367 & 7,886 & 8,241 & -355 \\
\hline $\begin{array}{l}\text { Long-term cardiovascular } \\
\text { treatment cost after year } 1 \text { or year } \\
3^{c}\end{array}$ & 7,006 & 6,906 & 100 & 5,593 & 5,489 & 104 \\
\hline Total cost ${ }^{\mathrm{c}}$ & 12,843 & 13,110 & -267 & 13,480 & 13,730 & -250 \\
\hline QALYs per patient ${ }^{\mathrm{c}}$ & 6.26 & 6.17 & 0.09 & 6.43 & 6.32 & 0.11 \\
\hline ICER $(£ \text { per QALY gained })^{\mathrm{c}}$ & \multicolumn{3}{|c|}{ Bivalirudin strategy dominant $^{\mathrm{d}}$} & \multicolumn{3}{|c|}{ Bivalirudin strategy dominant $^{\mathrm{d}}$} \\
\hline
\end{tabular}

a In the main model, detailed modelling of clinical events covered the first year after the initial STEMI event. In the alternative model, this time period was extended to three years.

b Excluding initial hospitalisation ward costs.

c Discounted at $3.5 \%$ per year, starting in year 2 .

d If one strategy dominates the alternative, i.e. if it is more clinically effective and less costly, calculating an ICER is numerically possible but the result has no meaningful interpretation. Differences in effectiveness and cosr are therefore shown side-by-side.

$\Delta$, difference; GPI, glycoprotein IIb/IIIa inhibitor; H-GPI, heparin and glycoprotein IIb/IIIa inhibitor; ICER, incremental cost-effectiveness ratio; QALY, quality-adjusted life year. 


\section{Sensitivity and scenario analyses}

The dominance of bivalirudin was maintained in all deterministic sensitivity analyses exploring the impact of parameter uncertainty, except if the length of stay differences between strategies in normal ward and in intensive or coronary care were varied jointly on the basis of their $95 \%$ confidence intervals (CIs). This led to a net cost of the bivalirudin strategy of $£ 37$, resulting in an incremental cost-effectiveness ratio (ICER) of $£ 415$ per QALY gained.

Detailed sensitivity and scenario analysis results are available online (S3).

In the probabilistic sensitivity analysis (fig. 2), the bivalirudin strategy was dominant (i.e. was cost-saving and showed a QALY gain) in 9,501 (95.0\%) of 10,000 simulation runs. The cost-effectiveness threshold of $£ 20,000$ per QALY gained was met in 9,924 (99.2\%) of 10,000 runs. Probabilistic analysis of the alternative model yielded similar results.

The dominance of bivalirudin was also maintained in most of the scenario analyses. It was lost but a favourable ICER of $£ 1,764$ per QALY gained was still seen when eptifibatide was assumed to be the only GPI used. In the extreme case scenario combining several unfavourable assumptions (100\% eptifibatide use; $100 \%$ radial arterial access use with a correspondingly reduced survival advantage for bivalirudin; no difference in initial hospitalisation length of stay), the ICER was $£ 5,428$ per QALY gained. 


\section{DISCUSSION}

Our incremental cost-effectiveness analysis indicates that, in STEMI patients undergoing PPCI, the use of bivalirudin yields a QALY gain and is cost-saving compared to H-GPI-based anticoagulation. It is hence dominant from the perspective of the UK health system. Results from two model versions, with detailed modelling of clinical events until the end of year 1 or year 3, are highly consistent. Dominance is maintained over a wide range of sensitivity and scenario results. Even under very unfavourable assumptions, the incremental costeffectiveness remains better than $£ 6,000$ per QALY gained.

\section{Comparison with published studies}

To our knowledge this is the first incremental cost-effectiveness analysis of bivalirudin use in PPCI. Guidance documents issued by NICE and by the Scottish Medicines Consortium were informed by the analysis presented here and by an earlier version reflecting the Scottish setting.[12, 37] A previous cost-effectiveness analysis for UK patients with NSTE-ACS used the same analytical framework but favoured bivalirudin less strongly than the present analysis.[13] This result is consistent given smaller clinical effect sizes and longer anticoagulant and GPI administration times. Other economic studies of bivalirudin were mostly cost studies with limited time horizons. They reported bivalirudin use to be cost saving in different indications.[38] A large administrative database study of PPCI patients in the USA found that from a hospital perspective, 30-day costs were $9 \%$ lower if bivalirudin was used instead of H-GPI.[39] This result matches the 9\% cost difference we found in our analysis at the end of year 1 . 


\section{Strengths and weaknesses}

International randomised clinical trial results representing a high level of clinical evidence formed the basis of this analysis. It should be noted that the HORIZONS-AMI trial used an open-label design to cope with technical complexities.[5] Predominant use of the HORIZONS-AMI intention-to-treat data allowed for a high level of internal consistency of model input parameters. The use of local data on long-term survival, utilities, length of stay and unit costs allowed for an adjustment to the UK health service environment. However, issues of transferability of clinical trial results remain and some related adjustments are subject to limitations. For example, results for the 214 HORIZONS-AMI patients with radial arterial access were affected by unacceptable statistical uncertainty. Approximation of the impact of radial access use was therefore based on assumptions of no access site bleedings in the affected patients and of a reduced length of stay advantage for bivalirudin. Initial hospitalisation length of stay in the H-GPI strategy was taken from a UK source[22] and the reduction seen in the HORIZONS-AMI bivalirudin arm was applied proportionally. It is unproven whether such a proportional reduction can actually be achieved in UK routine practice, although two US database analyses have observed such an effect.[10, 39] The use of alternative GPI substances in HORIZONS-AMI was influenced by the protocol. For an adjustment to UK practice, data on all PCI patients in the UK were available but no data on STEMI PPCI patients.[16] Thus, the use of abciximab, the most expensive GPI, was probably underestimated. In fact, a modelling study by Goodacre et al. that formed part of the English NIAP project assumed 100\% abciximab use in STEMI PPCI patients treated with H-GPI.[22] Estimating long-term survival required adjustment of data collected 10-15 years ago.[20]

The approach to sensitivity analysis took into account increased parameter uncertainty in some model inputs such as long-term annual cardiovascular treatment costs and bleeding costs, which arose from lack of data. A possible reduction of the survival advantage for 
bivalirudin in situations of increased use of radial arterial access was approximated in scenario analysis. The impact on cost-effectiveness was rather limited.

Structurally, the model did not link long-term survival and costs to the occurrence of clinical events during the initial one-year or three-year period. Given a lack of suitable input data, identical mortality risks were assumed for survivors of this period. However, the alternative model (with detailed modelling of clinical events until the end of year 3) demonstrated differential survival rates and a sustained survival advantage in years 2 and 3 for bivalirudin-treated patients, which resulted in an increased QALY gain. Hence, the above assumption may have biased results towards the conservative. While the model correctly covered the occurrence of multiple events of different type in one patient, a simplifying assumption of a maximum of one clinical event per event type and patient was made. The impact of this choice was assessed to be marginal. The utility impact of clinical events after the initial STEMI event was covered on a summary basis but could not be based on the actual pattern of event occurrence in the HORIZONS-AMI trial, where more events occurred in the H-GPI strategy.

Some practical advantages of bivalirudin such as simpler administration and reduced monitoring requirements were not taken into account.

\section{Further research}

We focused on comparing bivalirudin against H-GPI which is considered the current standard of care.[1, 2] A common background treatment of aspirin and a thienopyridine was assumed; in the HORIZONS-AMI trial, clopidogrel was overwhelmingly used. Our results are therefore only formally valid for this approach. Combination with newer thienopyridines such as prasugrel requires further study but there are no obvious reasons to expect fundamentally different health economic characteristics.[40] Alternative comparator strategies such as heparin and provisional GPI or heparin alone would require evaluation in large randomised 
trials of STEMI patients; for heparin alone indirect treatment comparisons using older trials of heparin alone versus H-GPI might be used for an approximate assessment. Based on subgroup analyses of the HORIZONS-AMI data and observational studies, it is currently being discussed whether bivalirudin should be administered in conjunction with heparin.[41-43] Given the minimal cost of heparin, a negative impact on the cost-effectiveness of bivalirudin would be unlikely.

In order to gain additional insights into the implications of bivalirudin use in the UK, clinical registries of STEMI PPCI patients could be used. Studies of mixed PCI populations conducted in the USA indicate the feasibility of observational approaches.[10, 39] In order to provide meaningful data, registries should record details of anticoagulation strategies and related drug use and bleeding events, in addition to standard parameters. Mechanisms should be implemented to avoid underreporting of bleeding events. The duration of clinical follow-up should be at least one year.

\section{Conclusion}

In STEMI patients undergoing PPCI, the use of bivalirudin instead of H-GPI is cost-effective, and offers a high probability of dominance, from the perspective of the UK health system. Background treatment with aspirin and clopidogrel is assumed. Extensive sensitivity and scenario analyses confirmed this result to be robust. 


\section{ACKNOWLEDGEMENTS}

None.

\section{COMPETING INTERESTS}

M.S. received consultancy fees and research funding from The Medicines Company via employment institution. T.T. and S.P. were employees of The Medicines Company at the time of study conduct. T.D.S. has no conflict of interest. D.B. and A.B. received speaker's fees and research grants from The Medicines Company.

\section{FUNDING}

This research was funded by The Medicines Company, Parsippany, NJ, USA. It was performed to inform a Single Technology Appraisal by the National Institute for Health and Clinical Excellence.

\section{COPYRIGHT LICENCE STATEMENT}

The Corresponding Author has the right to grant on behalf of all authors and does grant on behalf of all authors, a worldwide licence to the Publishers and its licensees in perpetuity, in all forms, formats and media (whether known now or created in the future), to i) publish, 
reproduce, distribute, display and store the Contribution, ii) translate the Contribution into other languages, create adaptations, reprints, include within collections and create summaries, extracts and/or, abstracts of the Contribution, iii) create any other derivative work(s) based on the Contribution, iv) to exploit all subsidiary rights in the Contribution, v) the inclusion of electronic links from the Contribution to third party material where-ever it may be located; and, vi) licence any third party to do any or all of the above.

\section{REFERENCES}

1. Van de Werf F, Bax J, Betriu A, et al. Management of acute myocardial infarction in patients presenting with persistent ST-segment elevation: the Task Force on the Management of ST-Segment Elevation Acute Myocardial Infarction of the European Society of Cardiology. Eur Heart J 2008;29:2909-45.

2. DH Vascular Programme Team. Treatment of Heart Attack National Guidance. Final Report of the National Infarct Angioplasty Project (NIAP). London: Department of Health, 2008.

3. Keeley EC, Boura JA, Grines CL. Primary angioplasty versus intravenous thrombolytic therapy for acute myocardial infarction: a quantitative review of 23 randomised trials. Lancet 2003;361:13-20.

4. Kandzari DE, Hasselblad V, Tcheng JE, et al. Improved clinical outcomes with abciximab therapy in acute myocardial infarction: a systematic overview of randomized clinical trials. Am Heart J 2004;147:457-62.

5. Stone GW, Witzenbichler B, Guagliumi G, et al. Bivalirudin during primary PCI in acute myocardial infarction. N Engl J Med 2008;358:2218-30.

6. Mehran R, Lansky AJ, Witzenbichler B, et al. Bivalirudin in patients undergoing primary angioplasty for acute myocardial infarction (HORIZONS-AMI): 1-year results of a randomised controlled trial. Lancet 2009;374:1149-59.

7. Stone GW, Witzenbichler B, Guagliumi G, et al. Heparin plus a glycoprotein IIb/IIIa inhibitor versus bivalirudin monotherapy and paclitaxel-eluting stents versus bare- 
metal stents in acute myocardial infarction (HORIZONS-AMI): final 3-year results from a multicentre, randomised controlled trial. Lancet 2011;377:2193-204.

8. Lincoff AM, Kleiman NS, Kereiakes DJ, et al. Long-term efficacy of bivalirudin and provisional glycoprotein IIb/IIIa blockade vs heparin and planned glycoprotein IIb/IIIa blockade during percutaneous coronary revascularization: REPLACE-2 randomized trial. JAMA 2004;292:696-703.

9. Stone GW, Ware JH, Bertrand ME, et al. Antithrombotic strategies in patients with acute coronary syndromes undergoing early invasive management: one-year results from the ACUITY trial. JAMA 2007;298:2497-506.

10. Rassen JA, Mittleman MA, Glynn RJ, et al. Safety and effectiveness of bivalirudin in routine care of patients undergoing percutaneous coronary intervention. Eur Heart J 2010;31:561-72.

11. Lopes RD, Peterson ED, Chen AY, et al. Antithrombotic strategy in non-ST-segment elevation myocardial infarction patients undergoing percutaneous coronary intervention: insights from the ACTION (Acute Coronary Treatment and Intervention Outcomes Network) Registry. JACC Cardiovasc Interv 2010;3:669-77.

12. National Institute for Health and Clinical Excellence. Bivalirudin for the treatment of ST-segment-elevation myocardial infarction. NICE technology appraisal guidance 230. http://guidance.nice.org.uk/TA230 (accessed 02 Aug 2011).

13. Schwenkglenks M, Brazier JE, Szucs TD, et al. Cost-effectiveness of bivalirudin versus heparin plus glycoprotein IIb/IIIa inhibitor in the treatment of non-ST-segment elevation acute coronary syndromes. Value Health 2011;14:24-33.

14. Verheugt FW, Steinhubl SR, Hamon M, et al. Incidence, prognostic impact, and influence of antithrombotic therapy on access and nonaccess site bleeding in percutaneous coronary intervention. JACC Cardiovasc Interv 2011;4:191-7.

15. National Institute for Health and Clinical Excellence. Guide to the methods of technology appraisal. London: NICE, 2008.

16. British Cardiovascular Intervention Society. BCIS Audit Returns. Adult Interventional Procedures Jan 2009 to Dec 2009. http://www.bcis.org.uk/resources/BCIS_Audit_2009_data_version_08-102010_for_web.pdf (accessed 15 Dec 2010).

17. Jolly SS, Yusuf S, Cairns J, et al. Radial versus femoral access for coronary angiography and intervention in patients with acute coronary syndromes (RIVAL): a randomised, parallel group, multicentre trial. Lancet 2011;377:1409-20. 
18. Beck JR, Kassirer JP, Pauker SG. A convenient approximation of life expectancy (the "DEALE"). I. Validation of the method. Am J Med 1982;73:883-8.

19. Office for National Statistics. Interim Life Tables, England and Wales, 1980-82 to 2007-09.

http://www.statistics.gov.uk/downloads/theme_population/Interim_Life/iltew-reg.xls (accessed 15 Dec 2010).

20. Palmer S, Sculpher M, Philips Z, et al. A cost-effectiveness model comparing alternative management strategies for the use of glycoprotein IIB/IIIA antagonists in non-ST-elevation acute myocardial infarction. NICE Appraisal Report. London: NICE, 2002.

21. Lacey EA, Walters SJ. Continuing inequality: gender and social class influences on self perceived health after a heart attack. J Epidemiol Community Health 2003;57:6227.

22. Goodacre S, et al. Evaluation of the National Infarct Angioplasty Project Report for the National Co-ordinating Centre for NHS Service Delivery and Organisation R\&D. Sheffield: NCCSDO, 2008.

23. Hill RA, Boland A, Dickson R, et al. Drug-eluting stents: a systematic review and economic evaluation. Health Technol Assess 2007;11:iii,xi-221.

24. Bravo Vergel Y, Palmer S, Asseburg C, et al. The Cost-Effectiveness of Primary Angioplasty Compared to Thrombolytic Therapy for Acute Myocardial Infarction in the UK NHS. York: University of York, 2006.

25. MIMS. www.mims.co.uk (accessed 29 Nov 2010).

26. Department of Health. NHS reference costs 2005-06. http://www.dh.gov.uk/en/Publicationsandstatistics/Publications/PublicationsPolicyAn dGuidance/DH_062884 (accessed 15 Dec 2010).

27. Department of Health. NHS reference costs 2008-09. http://www.dh.gov.uk/en/Publicationsandstatistics/Publications/PublicationsPolicyAn dGuidance/DH_111591 (accessed 15 Dec 2010).

28. Denvir MA, Lee AJ, Rysdale J, et al. Comparing performance between coronary intervention centres requires detailed case-mix adjusted analysis. J Public Health (Oxf) 2004;26:177-84.

29. Information and Statistics Scotland. Scottish Financial Returns (SFRs) 2007. http://www.isdscotland.org/isd/5800.html (accessed 30 Jun 2009). 
30. Hlatky MA, Boothroyd DB, Brooks MM, et al. Clinical correlates of the initial and long-term cost of coronary bypass surgery and coronary angioplasty. Am Heart J 1999;138:376-83.

31. Bravo Vergel Y, Palmer S, Asseburg C, et al. Is primary angioplasty cost effective in the UK? Results of a comprehensive decision analysis. Heart 2007;93:1238-43.

32. Cohen DJ, Lincoff AM, Lavelle TA, et al. Economic evaluation of bivalirudin with provisional glycoprotein IIB/IIIA inhibition versus heparin with routine glycoprotein IIB/IIIA inhibition for percutaneous coronary intervention: results from the REPLACE-2 trial. J Am Coll Cardiol 2004;44:1792-800.

33. Department of Health. NHS reference costs 2003 and National tariff 2004: payment by results core tools 2004 .

http://www.dh.gov.uk/en/Publicationsandstatistics/Publications/PublicationsPolicyAn dGuidance/DH_4070195 (accessed 15 Dec 2010).

34. Curtis L. Unit Costs of Health and Social Care 2009. Pay \& Prices Index for Hospital \& Community Health Services. Canterbury: Personal Social Services Research Unit, 2010 .

35. Pinto DS, Stone GW, Shi C, et al. Economic evaluation of bivalirudin with or without glycoprotein IIb/IIIa inhibition versus heparin with routine glycoprotein IIb/IIIa inhibition for early invasive management of acute coronary syndromes. $J$ Am Coll Cardiol 2008;52:1758-68.

36. Garratt KN, Cohen H, Fan W. Mortality reductions linked to bivalirudin use in unselected angioplasty patients with and without bleeding complications [abstract]. $J$ Am Coll Cardiol 2010;56(Suppl B):B28.

37. Scottish Medicines Consortium. Bivalirudin 250mg powder for concentrate for solution for injection or infusion (Angiox). SMC No. (638/10). http://www.scottishmedicines.org.uk/SMC_Advice/Advice/638_10_bivalirudin_Angi ox/bivalirudin_Angiox (accessed 02 Aug 2011).

38. Lyseng-Williamson KA. Bivalirudin: a pharmacoeconomic profile of its use in patients with acute coronary syndromes. Pharmacoeconomics 2011;29:343-59.

39. Olchanski N, Slawsky KA, Plent S, et al. Economic impact of switching to bivalirudin for a primary percutaneous coronary intervention in a US hospital. Hosp Pract (Minneap) 2010;38:138-46. 
40. Baumbach A, Johnson TW, Oriolo V, et al. Prasugrel and bivalirudin for primary angioplasty: Early results on stent thrombosis and bleeding. Int J Cardiol 2011;153:222-4.

41. Dangas GD, Caixeta A, Mehran R, et al. Frequency and predictors of stent thrombosis after percutaneous coronary intervention in acute myocardial infarction. Circulation 2011;123:1745-56.

42. Koutouzis M, Lagerqvist B, James S, et al. Unfractionated heparin administration in patients treated with bivalirudin during primary percutaneous coronary intervention is associated lower mortality and target lesion thrombosis: a report from the Swedish Coronary Angiography and Angioplasty Registry (SCAAR). Heart 2011;97:1484-8.

43. Langrish JP, Fox KA. Optimal antithrombotic treatment during primary percutaneous coronary intervention? Heart 2011;97:1459-60. 


\section{FIGURE LEGENDS}

Figure 1. Structure of decision analytic model

Figure 2. Main model - probabilistic sensitivity analysis results 


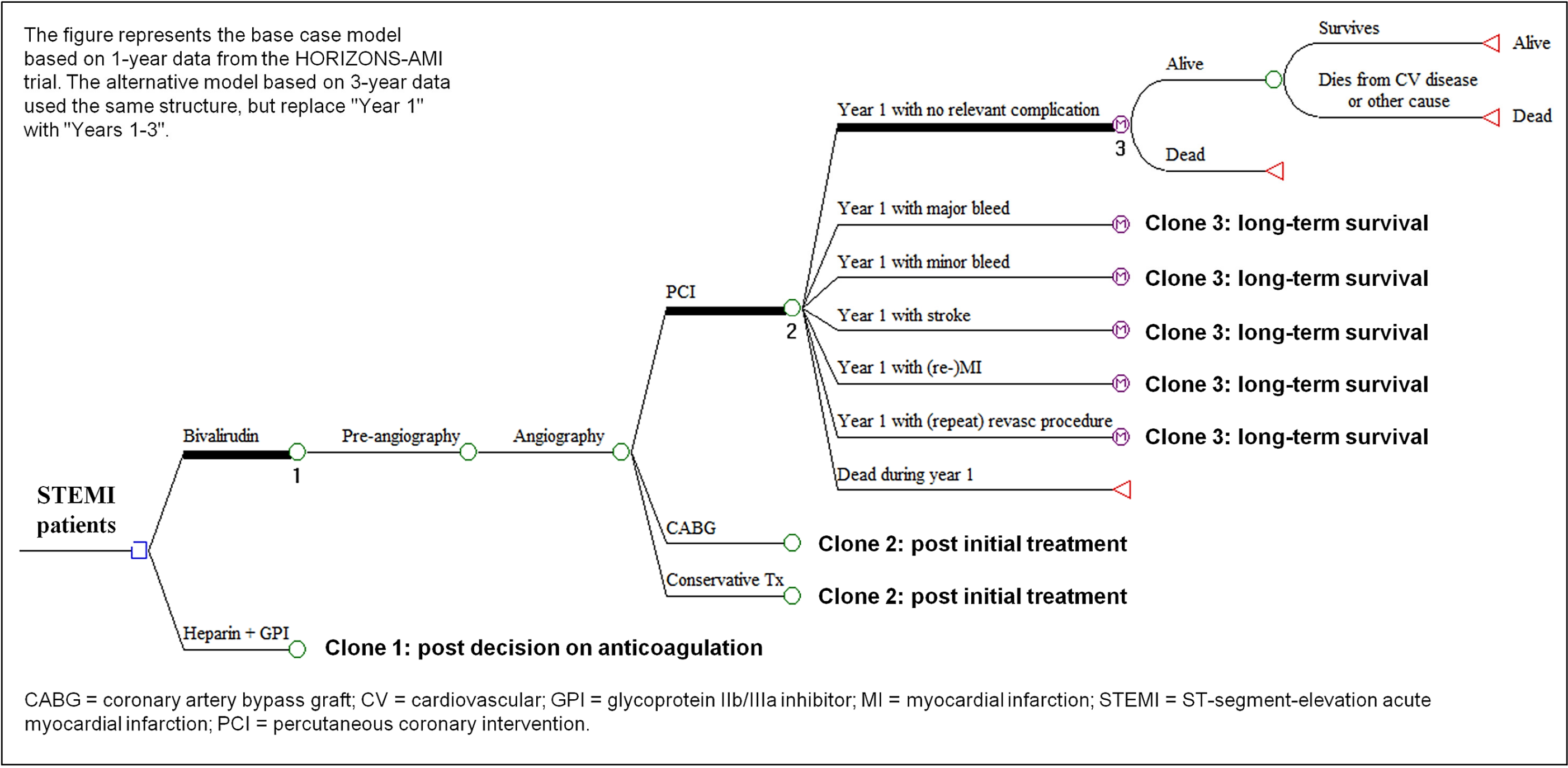




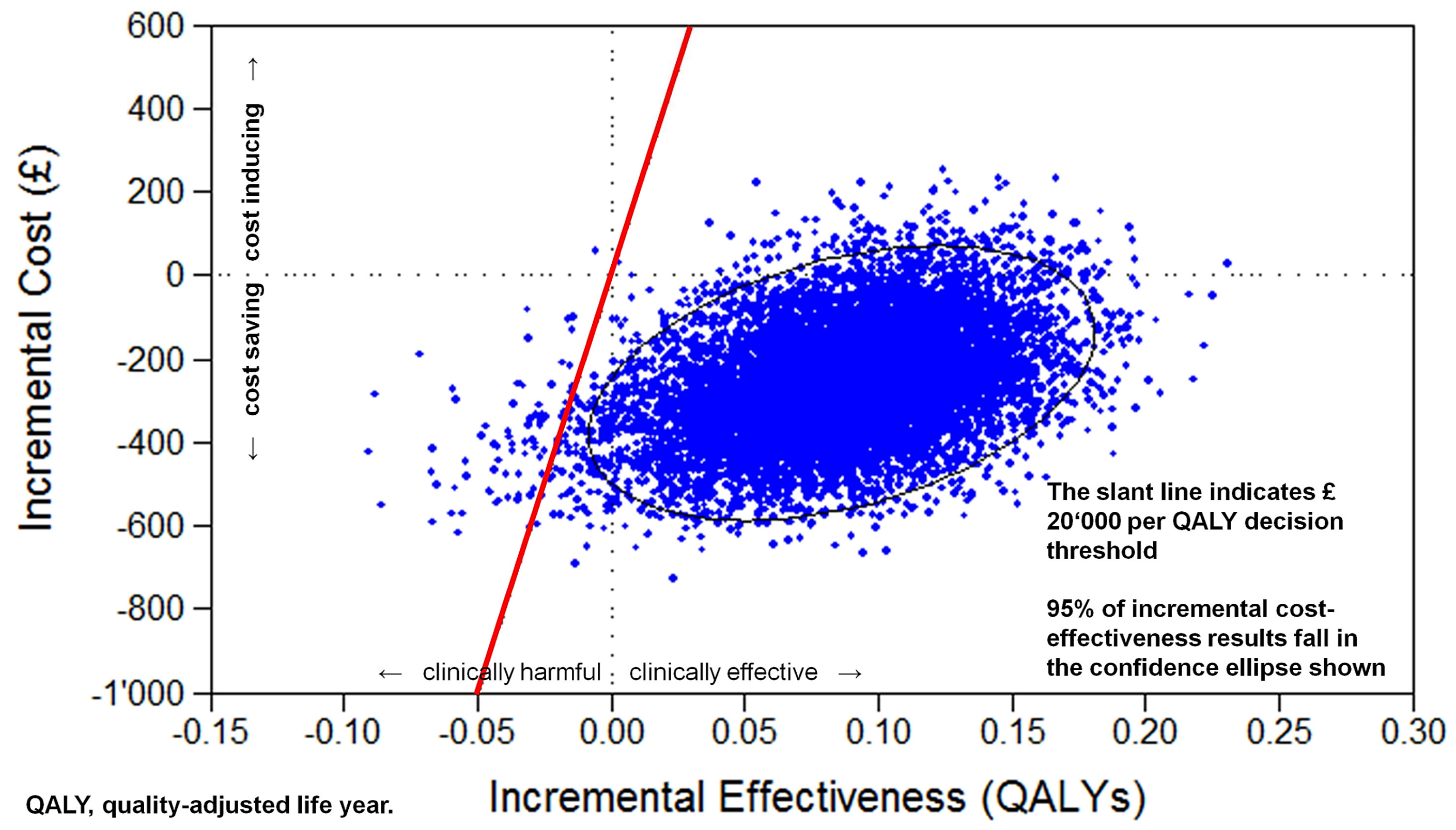

